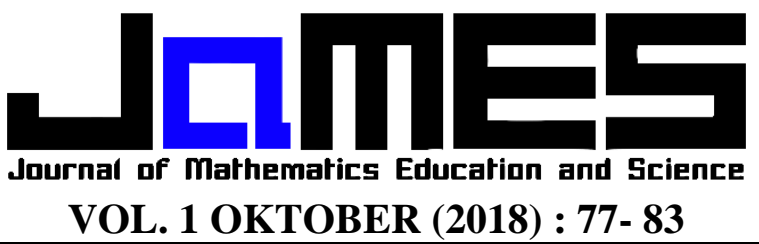

p-ISSN: 2621-1203 | https://doi.org/10.32665/james.v1iOctober.41 | e-ISSN: 2621-1211

\title{
ANALISIS VALIDITAS DAN PRAKTIKLITAS LEMBAR KERJA SISWA BERBASIS ETNOMATEMATIKA DALAM KONTEKS YOGYAKARTA
}

\author{
Rino Richardo ${ }^{1}$, Adhetia Martyanti ${ }^{2}$, Suhartini $^{3}$ \\ Universitas Alma Ata, rinorichardo@almaata.ac.id ${ }^{1}$ \\ Universitas Alma Ata, adhetia.martyanti@yahoo.co.id ${ }^{2}$ \\ Universitas Alma Ata, suhartini86@gmail.com ${ }^{3}$ \\ Received : 13 September 2018, Revised : 3 Oktober 2018, Accepted : 17 Oktober 2018 \\ (C) Mathematics Education Unugiri 2018
}

\begin{abstract}
The purpose of this research was to develop and produce valid and practical Student Worksheet based on ethnomathematics of Yogyakarta context. The subjects of this research were teachers and students of SMP Negeri 1 Piyungan Yogyakarta class VII E. The collecting data were used validation questionnaire and practical questionnaire. The result showed that the worksheets were very valid, and very practical. The validity rate was of 3,7, the practicality rate was $98 \%$ based on teachers asessment and rate was $82 \%$ based on students asessment.

Keywords : Student Worksheets, Valid, Practical, Ethnomathematics, Critical

Abstrak

Penelitian ini bertujuan untuk mengetahui apakah Lembar Kerja Siswa (LKS) berbasis etnomatematika dalam konteks Yogyakarta memenuhi kriteria Valid dan Praktis. Subjek Penelitian ini adalah guru dan siswa SMP Negeri 1 Piyungan Yogyakarta kelas VII E. Pengumpulan data menggunakan angket validasi dan angket kepraktisan. Hasil penelitian menunjukkan bahwa LKS memenuhi kriteria sangat valid dan sangat praktis. Dengan rata-rata nilai validitas adalah 3,7, rata-rata nilai kepraktisan adalah 98\% melalui penilaian guru serta rata-rata nilai kepraktisan adalah $82 \%$ melalui penilaian siswa.
\end{abstract}

Kata kunci : Lembar Kerja Siswa, Etnomatematika, Valid, Praktis, Kritis

\section{Pendahuluan}

Munculnya konsep revolusi industri 4.0 yang diperkenalkan oleh ekonom terkenal asal Jerman bernama Prof. Schwab, memberikan implikasi salah satunya adalah diperlukannya sumber daya manusia yang harus memiliki kapasitas/kemampuan kognitif sehingga mampu bertahan dan eksis di era tersebut. Salah satu kemampuan yang dibutuhkan adalah kemampuan berpikir kritis. Hal ini merupakan pekerjaan rumah bagi satuan pendidikan yang memiliki kewajiban mencetak peserta didik dengan kemampuan tersebut sehingga mampu berdayasaing pada era itu.
Ketika dikaitkan dalam pembelajaran, matematika merupakan salah satu mata pelajaran yang mampu memfasilitasi kemampuan berpikir kritis. Sebagaimana Setiana [1] menyatakan matematika sebagai salah satu disiplin ilmu yang diajarkan pada setiap jenjang pendidikan sekolah, diharapkan dapat memberikan sumbangan dalam rangka memfasilitasi kemampuan berpikir kritis siswa. Selanjutnya De Bono [2], salah satu mata pelajaran yang dianggap dapat mengembangkan kemampuan berpikir kritis adalah matematika. Pendapat tersebut menunjukkan bahwa matematika memiliki 
peranan yang sangat penting dalam mengembangkan kemampuan berpikir kritis.

Fachrurazi [3] mengutip pendapat Krulik dan Rudnick yang menyatakan bahwa yang termasuk berpikir kritis dalam matematika adalah berpikir yang menguji, mempertanyakan, menghubungkan, mengevaluasi setiap aspek yang ada dalam suatu masalah ataupun situasi tertentu. Melalui masalah yang diberikan kepada para siswa, menjadikan mereka terampil dalam memproses pengetahuan sehingga dapat menemukan dan menciptakan sesuatu [4]. Selain itu melalui kemampuan berpikir kritis, siswa mampu memahami konsep yang diperoleh menjadi lebih mendalam, sehingga proses belajar menjadi bermakna bagi siswa [5].

Masalah dalam matematika sering dikaitkan dengan kehidupan sehari-hari. Hal ini dimaksudkan agar konsep matematika yang diajarkan tidak hanya sebatas kemampuan komputasi, tetapi lebih pada kemampuan menganalisis sehingga mampu diterapkan dalam konteks yang konkrit. Sebagaimana Richardo, Abullah, dan Yuherni [6] berpendapat bahwa dengan kemampuan berpikir tersebut, diharapkan mampu terimplentasi dalam kehidupan sehari-hari, sehingga pembelajaran menjadi lebih bermakna. Dalam kurikulum 2013, kebermaknaan sebuah pembelajaran terhadap materi yang disampaikan seyogyanya mampu menyentuh aspek dalam kehidupan sehari-hari siswa, terlebih jika materi dihubungkan dengan pengalaman siswa, kehidupan sosial, bahkan menyentuh ranah seni dan budaya setempat. Dalam pembelajaran matematika, ternyata banyak kearifan lokal dan budaya yang dapat dikaitkan dengan matematika. proses mengaitkan konsep matematika dalam pembelajaran dengan kearifan budaya lokal disebut etnomatematika [7].

D'Ambrosio [8] menyatakan bahwa Matematika yang dipraktekkan oleh kelompok budaya seperti kelompok perkotaan dan pedesaan, kelompok buruh, anak-anak dari kelompok usia tertentu, atau masyarakat adat. Dalam konteks pembelajaran, diartikan bahwa bagaimana mempelajari konsep matematika dengan melalui pemaknaan yang kontekstual melalui aktivitas sosial dan budaya kelompok masyarakat setempat. Kondisi pembelajaran ini diharapkan mampu memberikan motivasi yang positif bahwa matematika tidak sebatas dengan angka-angka dan bilangan, serta memberikan nuansa keramahan dan kedekatan matematika dengan kehidupan siswa. Dengan kondisi ini, etnomatematika tentunya mampu memberikan hasil yang positif terhadap kualitas pembelajaran, sebagaimana hasil penelitian Ubayanti CS [9]. Integrasi budaya ke dalam kurikulum telah banyak dikembangkan di banyak negara dengan laporan yang positif terhadap kualitas pembelajaran matematika di berbagai jenjang pendidikan.

Berdasarkan hasil observasi awal melalui wawancara, penyebaran angket kepada peserta didik dan guru matematika serta hasil tes awal peserta didik, ditemukan bahwa (1) guru matematika belum sepenuhnya memfasilitasi siswa untuk mengembangkan berpikir kritisnya dalam pembelajaran, (2) guru belum memahami konsep etnomatematika, dan (3) berdasarkan hasil tes awal, para siswa masih mengalami kesulitan dalam menyelesaikan soal yang menuntut kemampuan berpikir kritis. Hasil observasi tersebut menunjukkan bahwa, terdapat urgensi untuk menciptakan sebuah inovasi pembelajaran yang didukung dengan penggunaan bahan ajar yang membantu siswa agar dapat mengembangkan kemampuan berpikir kritisnya. Salah satu bahan ajar yang bisa dikembangkan adalah Lembar Kerja Siswa (LKS) berbasis etnomatematika dalam konteks yogyakarta. Melalui LKS diharapkan dapat mengarahkan pola pikiran siswa sekaligus dapat menciptakan kemandirian siswa dalam mengkonstruksi pengetahuannya secara mandiri dan terarah [10]. Sehingga melalui adanya LKS yang dikembangkan ini, mampu memberikan kontribusi positif dan inovasi dalam pembelajaran untuk memfasilitasi kemampuan berpikir siswa melalui masalah-masalah yang terkait dengan kearifan lokal setempat 


\section{Metode Penelitian}

Penelitian eksperimen ini merupakan bagian dari penelitian pengembangan LKS berbasis etnomatematika dalam konteks Yogyakarta untuk meningkatkan kemampuan berpikir kritis siswa. Hasil dari penelitian ini dianalisis untuk melihat kevalidan dan kepraktisan dari LKS yang dikembangkan. Penelitian ini telah dilaksanakan dengan cara uji coba secara terbatas dikelas VII E SMP Negeri 1 Piyungan Yogyakarta. Instrumen yang digunakan dalam penelitian ini adalah lembar validasi LKS dosen pendidikan matematika, serta guru matematika. Sedangkan instrumen kepraktisan berupa angket untuk guru dan siswa. Data yang telah diperoleh, selanjutnya dianalisis dengan teknik analisis data deskriptif. Aspek validitas dianalisis dengan menggunakan rumus:

$$
R=\frac{\sum_{i=1}^{m} \sum_{j=1}^{n} V_{i j}}{m n}
$$

Keterangan:

$\mathrm{R}$ = rata-rata hasil penilaian dari para ahli

$V i j=$ skor hasil penilaian ahli ke-j terhadap kriteria i

$\mathrm{n} \quad$ = banyak ahli

$\mathrm{m}$ = banyak kriteria

Nilai rata-rata $(\mathrm{R})$ akan menentukan kriteria yang diperoleh dengan ketentuan sebagai berikut. [11]

Tabel 1. Kriteria Validitas

\begin{tabular}{cll}
\hline No & \multicolumn{1}{c}{$\begin{array}{c}\text { Rata-rata Penilaian } \\
\text { para ahli }\end{array}$} & Kriteria \\
\hline 1 & $\mathrm{R}>3,20$ & Sangat Valid \\
\hline 2 & $2,40<\mathrm{R} \leq 3,20$ & Valid \\
\hline 3 & $1,60<\mathrm{R} \leq 2,40$ & Cukup Valid \\
\hline 4 & $0,80<\mathrm{R} \leq 1,60$ & Kurang Valid \\
\hline 5 & $\mathrm{R}<0,80$ & Tidak Valid \\
\hline
\end{tabular}

LKS dikatakan valid jika reratanya $(\mathrm{R})>2,40$. (Izzati, 2012) [12]. Sedangkan Aspek Kepraktisan dianalisis dengan menggunakan rumus

$$
P=\frac{R}{S M} \times 100 \%
$$

Keterangan

$P \quad=$ nilai praktikalitas

$R$ = skor yang diperoleh

$S M=$ skor maksimum

Tabel 2. Kriteria Praktikalitas

\begin{tabular}{ccl}
\hline No & $\begin{array}{c}\text { Tingkat } \\
\text { Pencapaian }(\%)\end{array}$ & \multicolumn{1}{c}{ Kategori } \\
\hline 1 & $85<\mathrm{P} \leq 100$ & Sangat Praktis \\
\hline 2 & $75<\mathrm{P} \leq 85$ & Praktis \\
\hline 3 & $60<\mathrm{P} \leq 75$ & Cukup Praktis \\
\hline 4 & $55<\mathrm{P} \leq 60$ & Kurang Praktis \\
\hline 5 & $0<\mathrm{P} \leq 55$ & Tidak Praktis \\
\hline
\end{tabular}

LKS dikatakan praktis jika nilai kepraktisan (P) $>75 \%[12]$

\section{Pembahasan}

\subsection{Uji Validitas}

Lembar Kerja Siswa berbasis etnomatematika yang telah dikembangkan akan diuji kevalidan. Untuk mendapatkan data dalam rangka menguji kevalidan, maka digunakanlah lembar instrumen validasi yang telah divalidasi oleh 3 orang Dosen Pendidikan Matematika. Selanjutnya, kedua instrumen tersebut diberikan kepada beberapa validator untuk menilai tingkat validitas. Instrumen validitas diberikan kepada 5 orang validator, diantaranya 2 orang dosen pendidikan matematika, 1 orang dosen matematika murni, dan 2 orang guru matematika

Dilihat dari segi formatnya, LKS berbasis etnomatematika dinilai sangat valid oleh para validator. LKS tersebut sangat valid dari segi kejelasan pembagian materi, kejelasan sistem penomoran, tampilan yang menarik, seseimbangan antara teks dan ilustrasi, jenis dan ukuran huruf, pengaturan tata letak, dan kesesuaian ukuran fisik LKS dengan siswa SMP. Hasil validasi para validator disajikan dalam tabel 3 .

Dilihat dari Materinya, LKS berbasis etnomatematika dinilai sangat valid oleh para validator. LKS tersebut sangat valid dari segi Kebenaran materi, kesesuaian dengan RPP, kesesuaian dengan tujuan pembelajaran, kesesuaian dengan tingkat penalaran 
kemampuan siswa SMP, pengusaan simbol dan istilah, materi yang disajikan mampu memfasilitasi siswa dalam mengembangkan kemampuan berpikir kritis, keterkaitan materi dengan budaya yogyakarta, serta mencakup langkah-langkah pembelajaran saintific. Hasil validasi para validator disajikan dalam tabel 4 .

Tabel 3. Validitas ditinjau dari sisi Format

\begin{tabular}{|c|c|c|}
\hline \multirow{2}{*}{ No } & \multirow{2}{*}{ Aspek Yang Dinilai } & Rerata \\
\hline & & Validator \\
\hline \multirow[t]{9}{*}{1.} & Format LKS & \\
\hline & $\begin{array}{l}\text { a. Kejelasan } \\
\text { Materi. }\end{array}$ & 4 \\
\hline & $\begin{array}{l}\text { b. Kejelasan } \\
\text { penomoran. }\end{array}$ & 3,4 \\
\hline & c. Tampilan LKS Menarik. & 3,4 \\
\hline & $\begin{array}{l}\text { d. Keseimbangan antara teks } \\
\text { dan ilustrasi }\end{array}$ & 3,6 \\
\hline & e. Jenis dan ukuran Huruf & 3,8 \\
\hline & f. Pengaturan tata letak. & 3,8 \\
\hline & $\begin{array}{l}\text { g. Kesesuaian ukuran fisik } \\
\text { LKS dengan siswa SMP }\end{array}$ & 3,8 \\
\hline & Kriteria & $\begin{array}{c}\text { 3,69 } \\
\text { Sangat Valid }\end{array}$ \\
\hline
\end{tabular}

Tabel 4. Validitas ditinjau dari Materi

\begin{tabular}{|c|c|c|}
\hline \multirow{2}{*}{ No } & \multirow{2}{*}{ Aspek Yang Dinilai } & Rerata \\
\hline & & Validator \\
\hline \multirow[t]{10}{*}{2.} & Materi dan Isi LKS & \\
\hline & $\begin{array}{ll}\text { a. } & \text { Kebenaran } \\
& \text { Konsep/Materi }\end{array}$ & 3,4 \\
\hline & $\begin{array}{l}\text { b. Kesesuaian materi dan } \\
\text { RPP. }\end{array}$ & 4 \\
\hline & $\begin{array}{l}\text { c. Kesesuaian materi dengan } \\
\text { tujuan pembelajaran }\end{array}$ & 3,4 \\
\hline & $\begin{array}{l}\text { d. Kesesuaian tata urutan } \\
\text { materi pelajaran dengan } \\
\text { tingkat kemampuan siswa } \\
\text { SMP }\end{array}$ & 3 \\
\hline & $\begin{array}{l}\text { e. Konsistensi penggunaan } \\
\text { istilah dan simbol }\end{array}$ & 4 \\
\hline & $\begin{array}{l}\text { f. Dorongan uraian materi } \\
\text { terhadap pengembangan } \\
\text { kemampuan berpikir } \\
\text { kritis dan kreatif }\end{array}$ & 3,6 \\
\hline & $\begin{array}{llr}\text { g. } & \text { Keterkaitan materi } \\
\text { dengan konteks budaya di } \\
\text { yogyakarta }\end{array}$ & 3,8 \\
\hline & $\begin{array}{lll}\text { h. } & \begin{array}{l}\text { Mencakup } \\
\text { langkah saintifik }\end{array} & \text { langkah }\end{array}$ & 3,7 \\
\hline & Kriteria & $\begin{array}{c}3,6 \\
\text { Sangat Valid }\end{array}$ \\
\hline
\end{tabular}

Selanjutnya, dilihat dari konstruksi, LKS berbasis etnomatematika dinilai sangat valid oleh para validator. LKS tersebut sangat valid dari sisi pengunaan bahasa yang baik dan benar, sesuai EYD, kejelasan dalam petunjuk langkah-langkahnya, kesesuaian terkait istilah dan pertanyaan dengan kemampuan siswa SMP serta kecukupan tempat/space yang digunakan untuk isian jawaban . Hasil validasi para validator disajikan dalam tabel 5 .

Ditunjau dari sisi ilustrasi dan tata letak gambar, LKS berbasis etnomatematika dinilai sangat valid oleh para validator. LKS tersebut sangat valid dari sisi ilustrasi/gambar yang terakait langsung dengan konsep yang dibahas, ilustrasi gambar dibuat dengan tata letak yang efektif, ilustrasi gambar memperjelas konsep materi yang diberikan, serta memberikan tampilan yang menarik, jelas dan mudah dipahami. Hasil validasi para validator disajikan dalam tabel 6.

Ditunjau dari manfaat dan kegunaan, LKS berbasis etnomatematika dinilai sangat valid oleh para validator. LKS tersebut sangat valid dari sisi sebagai media yang dapat digunakan siswa untuk memfasilitasi menemukan konsep dari materi, sebagai media

Tabel 5. Validitas ditinjau dari Konstruksi

\begin{tabular}{|c|c|c|}
\hline No & Aspek Yang Dinilai & $\begin{array}{c}\text { Rerata } \\
\text { Validator }\end{array}$ \\
\hline \multirow[t]{10}{*}{3.} & Konstruksi & \\
\hline & $\begin{array}{ll}\text { a. } & \begin{array}{l}\text { Menggunakan bahasa } \\
\text { indonesia yang baik dan } \\
\text { benar. }\end{array}\end{array}$ & 3,4 \\
\hline & $\begin{array}{l}\text { b. Kesesuaian ejaan dan } \\
\text { bacaan sesuai dengan } \\
\text { EYD. }\end{array}$ & 3,8 \\
\hline & $\begin{array}{ll}\text { c. } & \text { Kesesuaian penggunaan } \\
\text { bahasa dengan taraf } \\
\text { berpikir, kemampuan } \\
\text { membaca, dan usia siswa } \\
\text { SMP }\end{array}$ & 3,6 \\
\hline & $\begin{array}{l}\text { d. Menggunakan istilah- } \\
\text { istilah secara tepat dan } \\
\text { mudah dipahami siswa } \\
\text { SMP }\end{array}$ & 3,8 \\
\hline & $\begin{array}{llc}\text { e. } & \begin{array}{l}\text { Kejelasan } \\
\text { menggunakan petunjuk }\end{array} \\
\end{array}$ & 3,8 \\
\hline & $\begin{array}{ll}\text { f. } & \text { Kalimat yang digunakan } \\
\text { komutatif dan interaktif }\end{array}$ & 4 \\
\hline & $\begin{array}{ll}\text { g. } & \text { Kesesuaian pertanyaan } \\
\text { yang digunakan dengan } \\
\text { tingkat kemampuan siswa } \\
\text { SMP }\end{array}$ & 3,2 \\
\hline & $\begin{array}{ll}\text { h. } & \text { Kecukupan tempat yang } \\
\text { disediakan untuk jawaban } \\
\text { siswa }\end{array}$ & 3,6 \\
\hline & Kriteria & $\begin{array}{c}3,65 \\
\text { Sangat Valid }\end{array}$ \\
\hline
\end{tabular}

http://journal.unugiri.ac.id/index.php?journal=JaMES 
Tabel 6. Validitas ditinjau dari Ilustrasi dan Tata Letak Gambar

\begin{tabular}{|c|c|c|}
\hline No & Aspek Yang Dinilai & $\begin{array}{c}\text { Rerata } \\
\text { Validator }\end{array}$ \\
\hline \multirow[t]{6}{*}{4.} & Ilustrasi dan tata letak gambar & \\
\hline & $\begin{array}{llr}\text { a. } & \text { LKS disertai } & \text { dengan } \\
\text { ilustrasi gambar yang } \\
\text { berkaitan } & \text { langsung } \\
\text { dengan materi pelajaran } \\
\text { atau konsep yang dibahas }\end{array}$ & 3,8 \\
\hline & $\begin{array}{lll}\text { b. } & \begin{array}{l}\text { Ilustrasi gambar } \\
\text { dengan tibuat } \\
\text { efektif }\end{array} & \\
\end{array}$ & 3,8 \\
\hline & $\begin{array}{llr}\text { c. } & \begin{array}{l}\text { Ilustrasi gambar } \\
\text { digunakan }\end{array} & \text { dapat } \\
\text { memperjelas } & \\
\text { konsep/materi } & \\
\end{array}$ & 3,8 \\
\hline & $\begin{array}{l}\text { d. Ilustrasi gambar menarik, } \\
\text { jelas terbaca, dan mudah } \\
\text { dipahami }\end{array}$ & 4 \\
\hline & Kriteria & $\begin{array}{c}\mathbf{3 , 8 5} \\
\text { Sangat Valid }\end{array}$ \\
\hline
\end{tabular}

untuk melatih kemandirian siswa dalam menemukan suatu konsep, menfasilitasi siswa untuk berkerjasama denga tim, serta dapat dijadikan sumber belajar alternatif dalam rangka meningkatkan kemampuan berpikir kritis siswa. Hasil validasi para validator disajikan dalam tabel berikut

Tabel 7. Validitas ditinjau dari Manfaat dan Kegunaan LKS

\begin{tabular}{|c|c|c|}
\hline No & Aspek Yang Dinilai & Rerata \\
\hline \multirow[t]{7}{*}{5.} & Manfaat dan Kegunaan LKS & \\
\hline & \begin{tabular}{ll} 
a. & \multicolumn{2}{l}{ Dapat digunakan sebagai } \\
mediabagi siswa untuk \\
menemukan & sebuah \\
konsep & dalam \\
pembelajaran matematika
\end{tabular} & 3,6 \\
\hline & $\begin{array}{l}\text { b. Memberi kesempatan } \\
\text { kepada siswa untuk } \\
\text { bekerja secara mandiri }\end{array}$ & 3,4 \\
\hline & \begin{tabular}{llr} 
c. & Memberi & \multicolumn{2}{c}{ kesempatan } \\
kepada siswa & untuk \\
bekerja & & secara \\
berkelompok dan & saling \\
bekerjasama & &
\end{tabular} & 4 \\
\hline & $\begin{array}{ll}\text { d. } & \text { Memberi kesempatan } \\
\text { kepada guru untuk } \\
\text { mengembangkan berbagai } \\
\text { macam kegiatan }\end{array}$ & 3,8 \\
\hline & $\begin{array}{l}\text { e. Memberikan alternatif } \\
\text { sumber belajar untuk } \\
\text { siswa }\end{array}$ & 3,6 \\
\hline & Kriteria & $\begin{array}{c}3,68 \\
\text { Sangat Valid }\end{array}$ \\
\hline
\end{tabular}

Berikut disajikan penilaian keseluruhan penilaian validator dari masing-masing aspek yang dinilai pada LKS

Tabel 8. Penilaian keseluruhan Aspek Penyusun LKS

\begin{tabular}{cllc}
\hline \multirow{2}{*}{ No } & \multicolumn{2}{c}{ Aspek Yang Dinilai } & Rerata \\
\cline { 2 - 4 } & \multicolumn{2}{c}{ Format LKS. } & Validator \\
\cline { 2 - 3 } & 2. & Materi dan Isi LKS & 3,69 \\
\hline 3. & Konstruksi & 3,65 \\
\hline \multirow{3}{*}{ 4. } & $\begin{array}{l}\text { Ilustrasi dan Tata } \\
\text { Letak Gambar }\end{array}$ & 3,85 \\
\hline \multirow{2}{*}{ 5. } & $\begin{array}{l}\text { Manfaat dan } \\
\text { Kegunaan LKS }\end{array}$ & 3,68 \\
\hline \multicolumn{2}{c}{ Kriteria } & $\begin{array}{c}\mathbf{3 . 7} \\
\text { Sangat Valid }\end{array}$ \\
\hline
\end{tabular}

Berdasarkan tabel tersebut, dapat disimpulkan bahwa LKS berbasis Etnomatematika dalam konteks yogyakarta berdasarkan penilaian dari keseluruhan aspek penyusun LKS melalui Validator berkriteria Sangat Valid dengan nilai rata-rata 3,7 .

\subsection{Uji Praktikalitas}

Selain uji Validitas, Lembar Kerja Siswa berbasis etnomatematika diuji juga kepraktisannya. Data kepraktisannya, diperoleh dengan memberikan angket kepraktisan kepada 2 orang guru bidang studi matematika dan siswa. Sebelum angket diberikan, maka angket terlebih dahulu divalidasi oleh 3 orang Dosen Pendidikan Matematika.

Tabel 9. Praktikalitas LKS

\begin{tabular}{|c|c|c|c|}
\hline \multirow{2}{*}{ No } & \multirow{2}{*}{ Aspek Yang Dinilai } & \multicolumn{2}{|c|}{ Validator } \\
\hline & & V1 & $\mathbf{V 2}$ \\
\hline \multirow[t]{3}{*}{1.} & Format LKS & & \\
\hline & $\begin{array}{lll}\text { a. } & \begin{array}{l}\text { Kemudahan } \\
\text { memahami format RPP. }\end{array}\end{array}$ & 4 & 4 \\
\hline & $\begin{array}{ll}\text { b. } & \begin{array}{l}\text { Kesesuaian ukuran huruf } \\
\text { yang digunakan. }\end{array} \\
\end{array}$ & 4 & 4 \\
\hline \multirow[t]{6}{*}{2.} & Materi/Isi & & \\
\hline & a. Kejelasan mengenai isi RPP. & 4 & 4 \\
\hline & $\begin{array}{lll}\text { b. } & \begin{array}{l}\text { Kemudahan } \\
\text { menerapkan RPP. }\end{array} & \text { dalam } \\
\end{array}$ & 4 & 4 \\
\hline & Kejelasan informasi. & 4 & 4 \\
\hline & $\begin{array}{lll}\text { d. } & \begin{array}{l}\text { Kejelasan pelaksanaan } \\
\text { kegiatan pembelajaran. }\end{array} \\
\end{array}$ & 4 & 4 \\
\hline & $\begin{array}{l}\text { e. Kesesuaian aktivitas siswa } \\
\text { dalam pembelajaran dengan } \\
\text { pendekatan pembelajaran } \\
\text { yang digunakan. }\end{array}$ & 4 & 4 \\
\hline
\end{tabular}




\begin{tabular}{|c|c|c|c|}
\hline \multirow{2}{*}{ No } & \multirow{2}{*}{ Aspek Yang Dinilai } & \multicolumn{2}{|c|}{ Validator } \\
\hline & & V1 & V2 \\
\hline & $\begin{array}{llr}\text { f. } & \begin{array}{l}\text { Kesesuaian } \\
\text { tingkat }\end{array} \text { perkembangan } \\
\text { kognitif siswa. }\end{array}$ & 4 & 4 \\
\hline & $\begin{array}{llr}\text { g. } & \text { Kesesuaian } & \text { materi dengan } \\
\text { konteks } & \text { budaya r di } \\
& \text { Yogyakarta } & \text { (berbasis } \\
& \text { etnomatematika Yogyakarta) }\end{array}$ & 4 & 4 \\
\hline & $\begin{array}{llr}\text { h. } & \begin{array}{l}\text { Kesesuaian } \\
\text { pembelajaran dengan alokasi }\end{array} \\
& \text { waktu. }\end{array}$ & 4 & 4 \\
\hline & $\begin{array}{ll}\text { i. } & \begin{array}{l}\text { Kesesuaian waktu penilaian } \\
\text { dengan alokasi waktu. }\end{array} \\
\end{array}$ & 3 & 3 \\
\hline \multirow[t]{7}{*}{3.} & Bahasa & & \\
\hline & $\begin{array}{lll}\text { a. } & \begin{array}{l}\text { Bahasa yang digunakan } \\
\text { komunikatif. }\end{array}\end{array}$ & 4 & 4 \\
\hline & $\begin{array}{ll}\text { b. } & \begin{array}{l}\text { Kalimat yang digunakan } \\
\text { mudah dipahami. }\end{array} \\
\end{array}$ & 4 & 4 \\
\hline & Jumlah & \multicolumn{2}{|c|}{102} \\
\hline & Skor Maksimum & \multicolumn{2}{|c|}{104} \\
\hline & Nilai Praktikalitas & \multicolumn{2}{|c|}{$98 \%$} \\
\hline & Kategori & \multicolumn{2}{|c|}{$\begin{array}{l}\text { Sangat } \\
\text { Praktis }\end{array}$} \\
\hline
\end{tabular}

Tabel tersebut menunjukkan bahwa terdapat tiga aspek kepraktisan diantaranya Format LKS, Materi/isi, serta penggunaan bahasa. Berdasarkan hasil penilaian kepraktisan oleh 2 orang guru matematika, disimpulkan bahwa LKS yang dikembangkan terkategori sangat praktis dengan nilai kepraktisan $98 \%$.

Selanjutnya, kepraktisan dilakukan oleh para siswa pada kelas ujicoba sebanyak 32 orang. Proses penilaian kepraktisan dilakukan dengan terlebih dahulu dengan memberikan pengalaman pembelajaran kepada siswa. Hasil analisis lembar penilaian siswa terhadap kepraktisan LKS diperoleh bahwa Nilai Kepraktisan sebesar $82 \%$ dengan kategori Praktis.

Berikut disajikan beberapa contoh bagian-bagian LKS berbasis etnomatematika dalam konteks yogyakarta yang telah dikembangkan

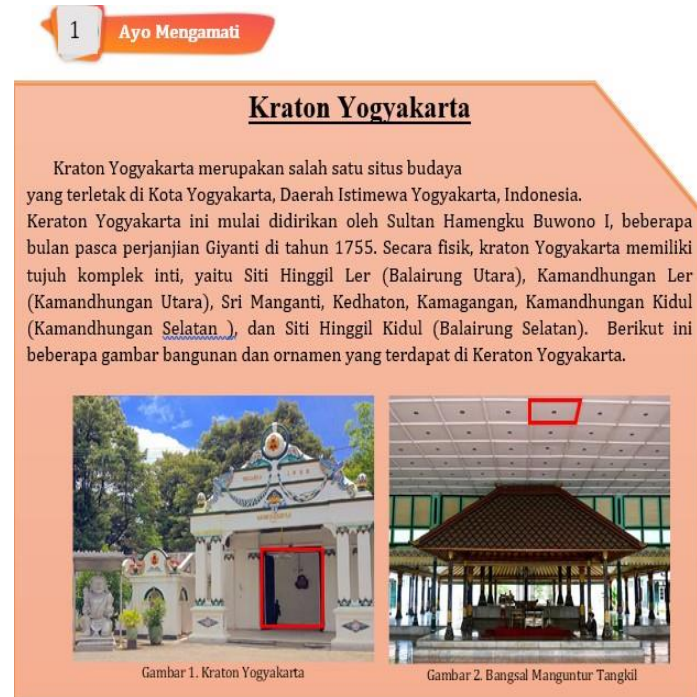

Perhatikan gambar $1-2$. Terdapat berbagai bentuk bangun datar yang dapat diamati pada gambar tersebut. Beberapa bangun tersebut antara lain persegi, persegi panjang, trapesium, dan segitiga.Pada gambar tersebut juga dapat diamati bahwa persegi memiliki 4 sisi dan sifat yang lain.

Coba perhatikan gambar persegi pada bidang gambar.

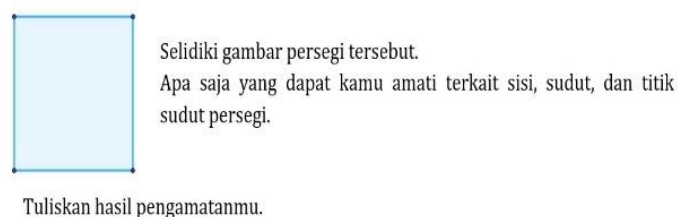

Gambar 1. Pengaitan subjek etnomatematika dengan konsep matematika

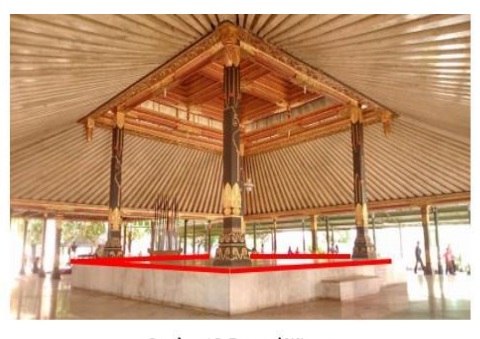

Gambar 18. Bangsal Witana
(Sumber: http://keraton

Bangsal Witana merupakan salah satu bangsal yang terdapat di Keraton Yogyakarta. Misalkan diketahui panggung yang berada di tengah bangsal berbentuk persegi dengan ukuran $4 \mathrm{~m}$.

a. Tentukan banyaknya keramik yang dipasang untuk menutupi permukaan atas panggung, jika keramik yang dipasang berukuran $50 \mathrm{~cm} \times 50 \mathrm{~cm}$.

b. Seandainya agar mampu menampung lebih banyak penari pada pergelaran tari, panggung pada bangsal Witana diperluas sehingga di setiap sisinya bertambah dua keramik berukuran $50 \mathrm{~cm} \times 50 \mathrm{~cm}$ seperti pada gambar berikut.

Untuk membuat hiasan dinding seperti gambar di samping diperlukan kain batik seluas $450 \mathrm{~cm}^{2}$.

Apabila akan dibuat hiasan dinding serupa dengan ukuran alas dan tingginya diperbesar menjadi dua kali alas dan tinggi semula, maka berapakah luas kain yang diperlukan?

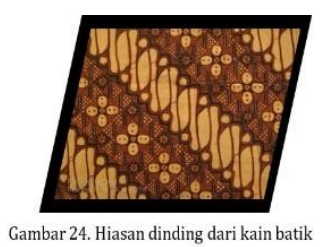

(Sumber: https://marinaelphick.files. wordpress.com/2013/11/image167.jpg)

Gambar 2. Soal-soal berbasis etnomatematika 


\section{Referensi}

[1] Setiana, Dafid Slamet. Urgensi Pengembangan Berpikir Kritis Dalam Pembelajaran Matematika. Prosiding Sendika. (2018), 376-383. 12 Mei, Purwerejo.

[2] De Bono, E. Mengajar Berpikir (Terjemahan oleh Soemardjo). Jakarta : Erlangga. (1990).

[3] Fachrurazi, Tesis PPs, Penerapan Pembelajaran Berbasis Masalah untuk Meningkatkan Kemampuan Berpikir Kritis dan Komunikasi Matematika Siswa SD, S3 Pendidikan Matematika, Program Pascasarjana, Universitas Pendidikan Indonesia, Indonesia, (2011).

[4] Abdullah, Ahmad Anis, and Rino Richardo. Menumbuhkan Kemampuan Berpikir Kritis Siswa Dalam Memilih Makanan Sehat Dengan Pembelajaran Literasi Matematika Berbasis Konteks. Jurnal Gantang 2.2 (2017): 89-97.

[5] Sholihah, Dyahsih Alin, and Widha Nur Shanti. Pembelajaran Konflik Kognitif Untuk Meningkatkan Kemampuan Berpikir Kritis Matematis Siswa. UNION: Jurnal Ilmiah Pendidikan Matematika 6.1 (2018), 71-82.

[6] Richardo, Rino, Ahmad Anis Abdullah, Yuherni. Identifikasi Kreativitas Siswa Slow Learner Dalam Memecahkan Masalah Matematika. De Fermat: Jurnal Pendidikan Matematika 1.1 (2018), 3945.

[7] Richardo, Rino. Peran Ethnomatematika dalam Penerapan Pembelajaran Matematika pada Kurikulum 2013. LITERASI (Jurnal Ilmu Pendidikan) 7.2 (2017), 118-125.
[8] D'Ambrosio,Ubiratan.Ethnomathematics

: Link Between Traditions and Modernity. Roterdam/ Taipei: Sense Publishers. (2001).

[9] Ubayanti, Chandra Sri, Happy Lumbatobing, Mayor MH Manurung. Eksplorasi Etnomatematika Pada Sero (Set Net): Budaya Masyarakat Kokas Fakfak Papua Barat. Jurnal Ilmiah Matematika dan Pembelajarannya 2.1 (2016), 11-17.

[10] Surmilasari, Nora. Pengembangan LKS Matematika Berbasis Konstruktivisme Untuk Pembelajaran Materi Perkalian Dua Matriks Di Kelas XII SMA. Prosiding Seminar Nasional Matematika dan Pendidikan Matematika FMIPA UNY. (2012), 635-642. 10 November, Yogyakarta.

[11] Muliyardi. 2006. Desertasi PPs Pengembangan Model Pembelajaran Matematika Menggunakan Komik di Kelas 1 Sekolah Dasar. S3 Pendidikan Matematika, Program Pascasarjana, Universitas Negeri Surabaya. (2011)

[12] Izzati, N. Desertasi PPs, Peningkatan Kemampuan Komunikasi Matematis dan Kemandirian Belajar Siswa SMP melalui Pendekatan Pendidikan Matematika Realistik.S3 Pendidikan Matematika, Program Pascasarjana, Universitas Pendidikan Indonesia, Indonesia, (2012). 
http://journal.unugiri.ac.id/index.php?journal=JaMES 